\title{
Antimicrobial photodynamic coatings reduce the microbial burden on environmental surfaces in public transportation - a field study in buses
}

\author{
Larissa Kalb 1, Pauline Bäßler 1, Wulf Schneider-Brachert ${ }^{2}$ and Daniel Bernhard Eckl 3,* \\ 1 Department of Dermatology, University Hospital Regensburg, 93053 Regensburg, Germany \\ 2 Department of Infection Control and Infectious Diseases, University Hospital, 93053 Regensburg, Germany \\ 3 Department of Microbiology, University of Regensburg, 93053 Regensburg, Germany \\ * Correspondence: Daniel.eckl@ur.de
}

\begin{abstract}
Millions of people use public transportation daily worldwide and frequently touch surfaces, thereby producing a reservoir of microorganisms on surfaces increasing the risk of transmission. Constant occupation makes sufficient cleaning difficult to achieve. Thus, an autonomous, permanent antimicrobial coating (AMC) could keep down the microbial burden on such surfaces. A photodynamic AMC was applied to frequently touched surfaces in buses. The microbial burden (colony forming units, cfu) was determined weekly and compared to equivalent surfaces in buses without AMC (references). The microbial burden ranged from $0-209 \mathrm{cfu} / \mathrm{cm}^{2}$ on references and from $0-54 \mathrm{cfu} / \mathrm{cm}^{2}$ on AMC. The means were $13.4 \pm 29.6 \mathrm{cfu} / \mathrm{cm}^{2}$ on references and $4.5 \pm 8.4 \mathrm{cfu} / \mathrm{cm}^{2}$ on AMC ( $\mathrm{p}<0.001)$. The difference of microbial burden on AMC and references was almost constant throughout the study. Considering a hygiene benchmark of $5 \mathrm{cfu} / \mathrm{cm}^{2}$, the data yield an absolute risk reduction of $22.6 \%$ and a relative risk reduction of $50.7 \%$. In conclusion, photodynamic AMC kept down the microbial burden, reducing the risk of transmission of microorganisms. AMC permanently and autonomously contributes to hygienic conditions on surfaces in public transportation. Photodynamic AMC therefore are suitable for reducing the microbial load and closing hygiene gaps in public transportation.
\end{abstract}

Keywords: antimicrobial coating; photodynamic inactivation; public transportation; AMC

\section{Introduction}

Microbes are present not only on surfaces in hospitals but also in all public areas including public transportation. In the Journal Nature, Rachel Ehrenberg mentioned a survey of genetic material from surfaces in the New York City's subway system that found more than 1,000 taxa, of which half were known and half of them are unknown $[1,2]$. More recently, researchers from all over the world created a global atlas containing 4,728 metagenomic samples from mass-transit systems in 60 cities over 3 years [3]. The study identified the most common antimicrobial resistance (AMR) genes among the metagenomic samples, which refer to antibiotics like macrolides, lincosamides, streptogramins and $\beta$-lactams [3]. Another study by Panagiotou and colleagues demonstrated that surfaces in public transport systems in the Mass Transit Railway of Hong Kong contribute to the spreading of antimicrobial resistance genes (ARG). Most likely due to hand-to-surface transmission, bacteria with these ARG are disseminated among the different lines. Especially ARG transmission for antibiotics like tetracycline and vancomycin seems to be fostered by public transportation [4]. Furthermore, the same study as well as the mentioned global atlas showed that most of bacterial contamination on 
surfaces originated from human skin as the most abundant metagenomes are derived from skin commensals $[3,4]$.

In the United States of America, people took almost 10 billion trips on public transportation in 2018 knowing that buses, subways and trains are - even macroscopically not always the cleanest spaces [5]. In public transportation, people frequently touch different surfaces such as buttons, railings, handgrips and seats. Being constantly occupied throughout the day, a sufficient cleaning inside vehicles is often difficult to achieve. Consequently, inanimate surfaces in public transportations are contaminated with microorganisms and viruses [5].

Unfortunately, only a few peer-reviewed studies are available quantifying the contamination of surfaces in public transportation with culture-based methods. An investigation in the public transport system and in public areas of a hospital in central London revealed a mean microbial burden on frequently touched surfaces of 12 colony forming units per $\mathrm{cm}^{2}\left(\mathrm{cfu} / \mathrm{cm}^{2}\right)$, whereas $8 \%$ of samples showed the presence of S. aureus [6]. A large-scale study on inanimate surfaces in different railway stations in England and Scotland revealed a bacterial contamination of up to $10^{7}-10^{8} \mathrm{cfu} / \mathrm{cm}^{2}$ whereas the sampling sites were excluded from daily cleaning routine [7]. Another study from Bangladesh found a median microbial load of $3 \times 10^{5} \mathrm{cfu} / \mathrm{cm}^{2}$ on handrails in public transport buses without cleaning [8]. Concerning the bacterial species, the metro in Mexico showed mainly Cutibacterium, Corynebacterium spp., Streptococcus spp., and Staphylococcus spp. [9], in New York city mainly Enterobacter cloacae [2] and Acinetobacter spp., and Methylobacterium in the subway of Barcelona [10]. When sampling surfaces in buses in Ohio, $17 \%$ of samples showed S. aureus [11].

Pathogenic bacteria, in particular antibiotic resistant bacteria, represent a major threat to human health [12]. When using public transportation, the touch of contaminated surfaces is unavoidable. Germs of colonized surfaces can be transferred by hands to mouth or nose, possibly causing infections. Thus, the use of public transportation adds an additional risk of transmission of pathogens via contaminated surfaces, as also shown for hospitals $[13,14]$.

To mitigate such a pathogen transmission, frequently touched inanimate surfaces can be equipped with an antimicrobial coating (AMC), initially developed to protect inanimate surfaces in health care settings [15]. An AMC acts permanently and autonomously and can thereby reduce the contamination of surfaces complementing cleaning and hygiene procedures. An AMC technology, which is based on the photodynamic principle, was already successfully tested performing a field study in two hospitals [16]. This thin AMC coating contains a special molecule called photosensitizer that generates the so-called singlet oxygen when the coating is exposed to ambient, visible light. The gaseous singlet oxygen molecule can leave the AMC via diffusion, reaches the microorganisms present on the coated surface and kill them via oxidative damages [16]. The results of that field study proved the action of singlet oxygen, which killed bacteria on the coated surface and thereby significantly reduced the contamination.

In this study, the same technology was applied in buses of the local public transportation in Regensburg, Germany. The antimicrobial efficacy of the AMC was tested under highly demanding real-life conditions via sampling of coated and control surfaces inside the buses by culture-based methods.

\section{Results}


Prior to experiments with coated and uncoated surfaces, 6 samplings $(\mathrm{N}=36)$ were performed in order to evaluate the surfaces in respect of their suitability for the actual study. The microbial burden on the six sampled surfaces ranged from 0.1 to $77.1 \mathrm{cfu} / \mathrm{cm}^{2}$. The median of the microbial burden was $5.75 \mathrm{cfu} / \mathrm{cm}^{2}$ and $12.6 \pm 19.6 \mathrm{cfu} / \mathrm{cm}^{2}$ for the mean value (Fig. 1).

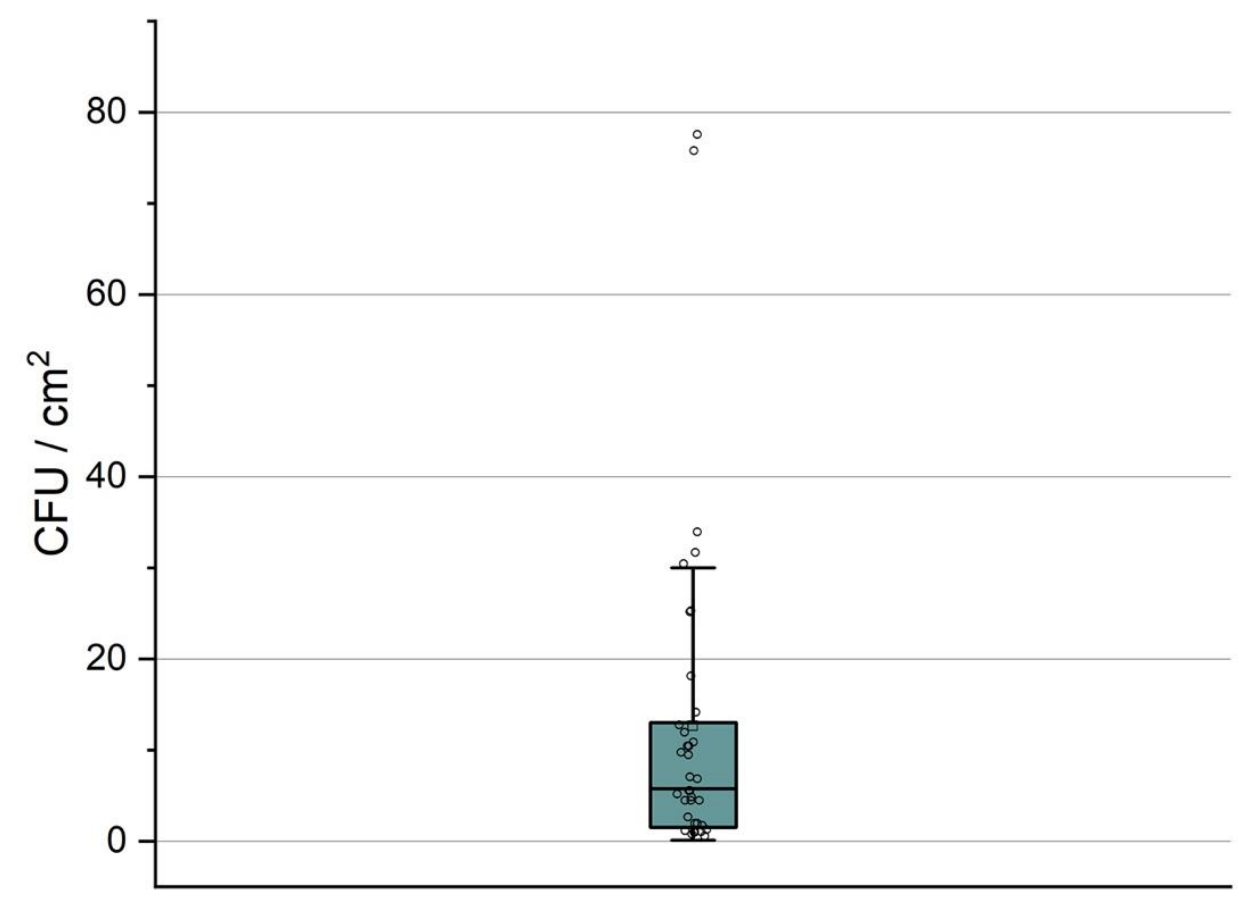

Figure 1. The values of microbial burden of the pre-study sampling are shown as box plots with the median and the quartile ranges.

14 samplings of the surfaces in the buses were performed at regular time intervals of one week to measure the bacterial counts on all included 24 surfaces of all buses. This yielded a total quantity of sample 336 bacterial samples, 168 on uncoated references and photodynamic coatings each.

The values of microbial burden ranged from $0-209 \mathrm{cfu} / \mathrm{cm}^{2}$ on uncoated references and $0-54 \mathrm{cfu} / \mathrm{cm}^{2}$ on sites with photodynamic coating. The median of bacterial burden on uncoated references or photodynamic coating was 3.8 or 1.8 , respectively. The mean values of bacterial counts were $13.4 \pm 29.6 \mathrm{cfu} / \mathrm{cm}^{2}$ on non-coated surfaces and $4.5 \pm 8.4$ $\mathrm{cfu} / \mathrm{cm}^{2}$ on photodynamic AMC. The difference between mean values on photodynamic coating and non-coated surfaces was statistically significant with $\mathrm{p}<0.001$ (Fig. 2). The obtained values obtained for the non-coated surface matched well with the results obtained from the initial sampling as mentioned above. 


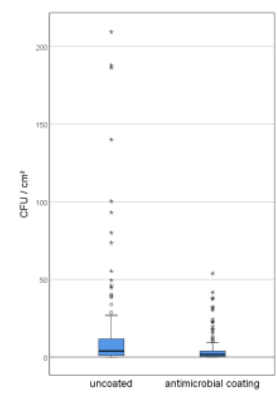

Figure 2. The values of microbial burden on uncoated references and on antimicrobial coatings are shown as box plots with the median and the quartile ranges.

Bacterial counts were further dichotomized using the following cut-offs. The frequency of numbers with bacterial counts of $>5 \mathrm{cfu} / \mathrm{cm}^{2}$ or $>2.5 \mathrm{cfu} / \mathrm{cm}^{2}$ were significantly less on sites with AMC as compared to uncoated references. When applying a benchmark of $5 \mathrm{cfu} / \mathrm{cm}^{2}$, the data yield an absolute risk reduction of $22.6 \%$ and a relative risk reduction of $50.7 \%$ for high bacteria counts on surface with an odds ratio of 0.35 ( $\mathrm{p}<0.001)$ (Table 1). Considering a benchmark of $2.5 \mathrm{cfu} / \mathrm{cm}^{2}$, the data yield an absolute risk reduction of $23.2 \%$ and a relative risk reduction of $39.0 \%$ for high bacteria counts on surface with an odds ratio of $0.39(\mathrm{p}<0.001)$ (Table 1$)$.

Table 1. Microbial burden regarding different benchmarks. The numbers given are the events concerning the given benchmark.

\begin{tabular}{ccccc}
\hline benchmarks & \multicolumn{2}{c}{$\begin{array}{c}\text { uncoated } \\
(\mathrm{N}=168)\end{array}$} & \multicolumn{2}{c}{ antimicrobial coating } \\
& number & percent & number & percent \\
& 68 & $40.5 \%$ & 107 & $63.7 \%$ \\
$\mathbf{c f u} / \mathbf{c m}^{2} \leq \mathbf{2 . 5}$ & 100 & $59.5 \%$ & 61 & $36.3 \%$ \\
$\mathbf{c f u} / \mathbf{c m}^{2}>\mathbf{2 . 5}$ & 93 & $55.4 \%$ & 131 & $78.0 \%$ \\
$\mathbf{c f u} / \mathbf{c m}^{2} \leq \mathbf{5}$ & 75 & $44.6 \%$ & 37 & $22.0 \%$ \\
$\mathbf{c f u} / \mathbf{c m}^{2}>\mathbf{5}$ & & & & \\
\hline
\end{tabular}


The mean values of microbial burden vary from sampling to sampling. However, the regression lines indicate an almost constant difference between the microbial burden found on uncoated references and photodynamic coating sites during the entire study (Fig. 3).

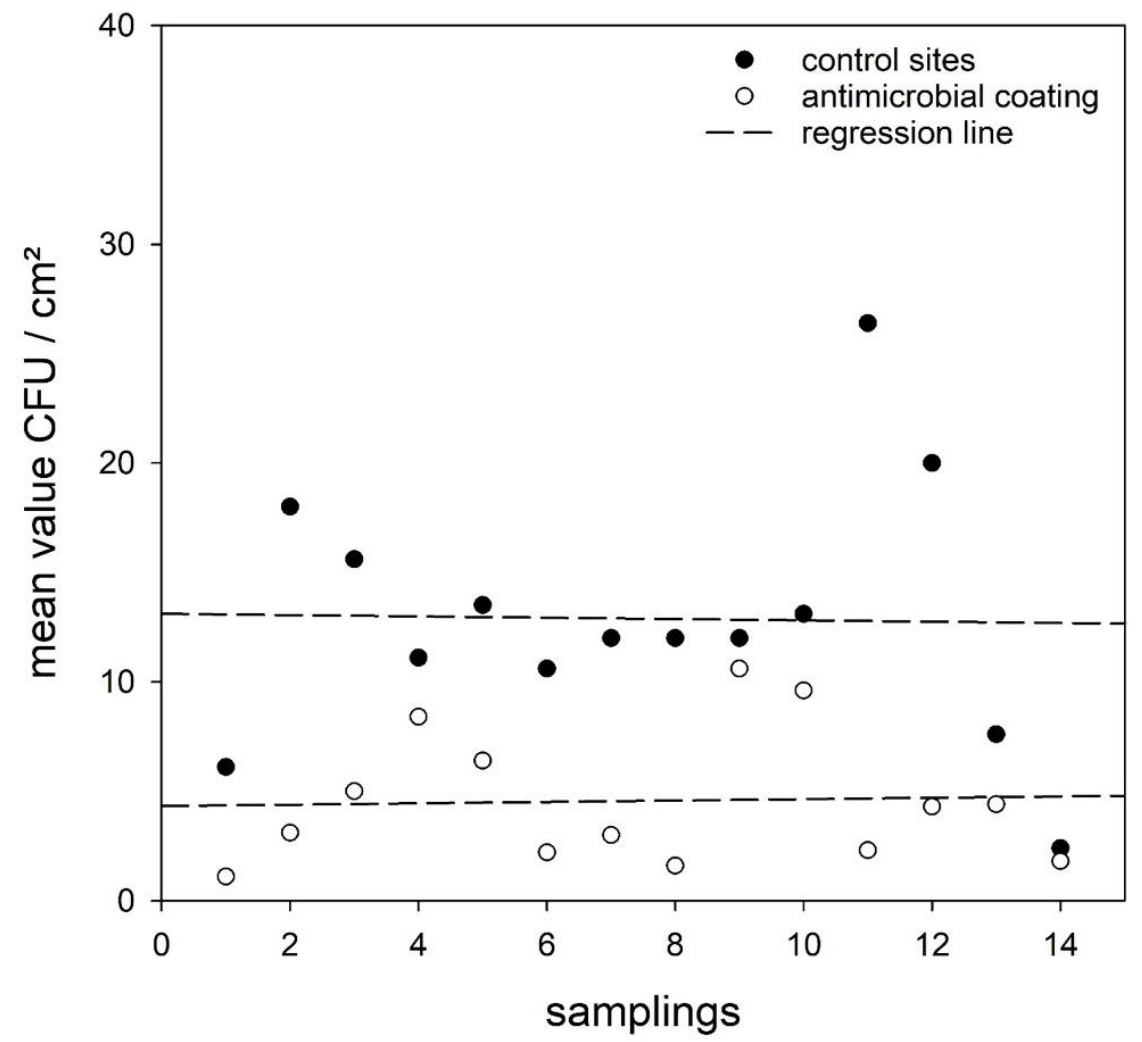

Figure 3. The mean values for all 14 samplings. The regression line indicates an almost constant difference between uncoated references without antimicrobial effect and the sites with the antimicrobial coating. 


\section{Discussion}

The present study clearly provided evidence that the photodynamic AMC can significantly decrease the bacterial burden on environmental surfaces in public transportation. Considering the study time of 2 months, the mean cfu value on the uncoated surface sites was $13.4 \pm 29.6 \mathrm{cfu} / \mathrm{cm}^{2}$, comparable to $12 \mathrm{cfu} / \mathrm{cm}^{2}$ found on surfaces in other public transportation [6]. In contrast, the surfaces with photodynamic AMC showed a mean of $4.5 \pm 8.4 \mathrm{cfu} / \mathrm{cm}^{2}$ only.

It is reasonable that the risk of microorganisms' transmission should increase with the microbial burden on touched surfaces. Therefore, surfaces in hygiene sensitive areas like food industry and health care settings should not exceed certain benchmarks, for instance $2.5 \mathrm{cfu} / \mathrm{cm}^{2}$ in hospitals $[17,18]$ and $5 \mathrm{cfu} / \mathrm{cm}^{2}$ on food-processing equipment [19]. These internationally recognized figures can serve as a starting point also for environmental surfaces in public transportation. According to these proposed values, statistical analysis of our study data yielded a relative risk reduction of about $51 \%$ for high bacteria counts on surface when considering a benchmark of $5 \mathrm{CFU} / \mathrm{cm}^{2}$ (odds ratio 0.35 , $\mathrm{p}<0.001$ ) (Table 1). Even for the smaller benchmark of $2.5 \mathrm{CFU} / \mathrm{cm}^{2}$, the relative risk reduction was $39 \%$ (odds ratio $0.38, \mathrm{p}<0.001$ ) (Table 1 ) for high bacteria counts on surface.

The standard deviation of $29.6 \mathrm{cfu} / \mathrm{cm}^{2}$ on uncoated surfaces indicates a clear fluctuation of the respective microbial burden, ranging from $0-209 \mathrm{cfu} / \mathrm{cm}^{2}$. This should be nothing out of the ordinary on normal because the actual microbial burden depends on the touch frequency, the survival time of the germs, the cleaning cycles and the cleaning quality. Without cleaning or disinfection, the survival time of microorganisms on environmental surfaces ranges from hours to several months and even viruses may stay infectious for up to several days $[20,21]$. Thus, regular sampling of the surfaces at fixed times should randomly detect the actual microbial burden.

In contrast to uncoated surfaces, the standard deviation was clearly smaller for the AMC $\left(8.4 \mathrm{cfu} / \mathrm{cm}^{2}\right)$ and the microbial burden ranged from $0-54 \mathrm{cfu} / \mathrm{cm}^{2}$ only. Thus, the photodynamic AMC can reduce the peak values of high bacterial counts and hence should reduce the risk of transmission through surfaces via the hands of any passenger or staff in public transportation. In addition, the regression analysis of the microbial burden on AMC and uncoated surfaces revealed that the AMC showed no decline in efficacy (Fig. $3)$.

The microbial burden on surfaces in public areas coheres with the skin microbiome due to recurrent touches [4]. In addition, sneezing and coughing deposits microorganisms and viruses along with droplets on inanimate surfaces in the environment [22]. In health care settings, clear evidence exist that contaminated human hands are a major vehicle for germs to inanimate surfaces $[23,24]$. Nevertheless, even in health care the compliance of hand hygiene and surface cleaning is not sufficient $[25,26]$.

Good hand hygiene is also important in public areas as it prevents the spread of diseases especially when travelling [27], studies suggest that $22 \%$ to $64 \%$ of international travelers become ill during or after travel [28]. However, the rates of hand washing in general population is highly varying. For instance, among food workers appropriate hand washing varied from 10 to 37\% [29]. Well-executed hand hygiene and compliance can reduce the risk of diarrheal disease transmission by between $23 \%$ and $48 \%[30,31]$.

A self-reported survey among the general populating in UK reported that only $61 \%$ wash their hands after toilet use [28]. A comparable study investigated the compliance rate of hand washing in Germany and women reported 'almost always' with a compliance of $30.8 \%$ (men: $20.3 \%$ ) in situations like public restroom visits [32], but one should 
consider the weaknesses of self-reported compliance compared to observational studies [28]. Currently, the situation might have improved due to the COVID pandemic. A study in 2020 showed that approximately $85 \%$ of U.S. adults are frequently engaged in handwashing or using hand sanitizer after contact with high-touch public surfaces, including only $72.4 \%$ of those aged $18-24$ years [33]. It was shown elsewhere that such a high hand hygiene compliance, induced by a pandemic, can decrease over time when the fear of infection with SARS-CoV-2 decreased [34].

In the light of the low compliance rates of hand hygiene, the presence of microbes on inanimate surfaces in public transportation is unavoidable. Cleaning or disinfection of all these numerous surfaces in buses, subways and trains seems to be a giant undertaking that would require substantial human resources and logistics. In addition, the disinfection of a surface acts only at the time of its execution and re-contamination inevitably occurs.

Thus, AMC can complement routine cleaning and disinfection procedures. AMC act independently and autonomously without assistance of the staff, in particular in the time gap of routine disinfections. That produces a permanent reduction of the mean number of microbes on such coated surfaces, thereby reducing the risk of transmission [15].

The antimicrobial efficacy of photodynamic AMC was already proven in laboratory experiments showing up to $4 \log _{10}$ of bacterial reduction for bacteria like $S$. aureus [16]. Such laboratory tests are necessary to conduct research and development linked to $\mathrm{AMC}$. However, laboratory tests are intrinsically artificial as it is impossible to mimic real life conditions in laboratories [15]. Thus, testing the efficacy of AMC should be mandatory in the subsequent field of application. The photodynamic AMC was recently tested in a field study in two hospitals on different surfaces for several months, revealing that the photodynamic AMC reduced the mean $\mathrm{cfu} / \mathrm{cm}^{2}$ and its standard deviation statistically significant [16].

At present, different technologies exist to equip inanimate surfaces with AMC, which may contain biocidal substances like silver, copper, titanium dioxide or quaternary ammoniums. Many of these AMC technologies were tested under laboratory conditions only, in particular with procedures using wet conditions only like ISO 22196 (bacteria) or ISO 21702 (virus) [15,35,36]. In case of silver AMC, it was already shown that the antimicrobial efficacy disappeared when surfaces are dry as in reality under normal ambient humidity conditions [37]. This is not surprising as most of the AMC biocides need a liquid on the inanimate surface for transportation of the biocidal substance from the AMC to the microbes. In addition, most of laboratory tests were performed on thoroughly cleaned AMC because soiling hampers the antimicrobial efficacy, in particular for copper and quaternary ammoniums [15].

The photodynamic approach is effective on normal dry surfaces because the biocidal singlet oxygen is a gaseous molecule, escaping the AMC after generation by the photosensitizer. Any soiling present on surfaces during the study obviously did not hamper the antimicrobial efficacy as shown by the significant reduction of microbial burden on the photodynamic AMC.

Another advantage of singlet oxygen is the fact that this molecule approaches the microbial cells from outside and oxidizes any double bonds in the microbial envelope. The cells are damaged without the need for penetration of singlet oxygen into the cells. Therefore, the photodynamic approach is considered to provoke no resistance in microorganisms [38]. 
This is an important issue when AMC technologies will be used on surfaces in public areas including public transport. Various microorganisms already show reduced sensitivity or resistance to biocidal substances like chlorhexidine, triclosan, silver, copper, and quaternary ammonium compounds [39,40]. In 2021, the European Medical Association stated that metals like copper, zinc and silver, which were used in AMC, are also known to elicit co-selection for AMR genes and thus might play a role in the development and spread of AMR [41]. The co- or cross resistance induced by such metals may lead to bacteria that show also an increased resistance to antibiotics [15,42].

Biocidal substances with a long-term stability like metals and quaternary ammonium may also reach the environment, and thereby for example influencing wastewater treatment plants in detrimental manners [43]. In addition, EU authorities demand safe chemicals while preventing harm to humans and the environment by avoiding substances of concern for non-essential use [44]. Singlet oxygen is short-lived and therefore remains active only in a thin layer of a few millimeters above AMC and cannot accumulate in the environment [45]. Singlet oxygen is safely applied in medicine like for photodynamic treatment of tumors and age-related macular disease of the retina for many years $[46,47]$.

In conclusion, the photodynamic AMC significantly reduced the mean bacterial burden on different inanimate surfaces in urban buses under real life conditions. In addition, the maximal detected bacterial burden $\left(\mathrm{cfu} / \mathrm{cm}^{2}\right)$ was clearly reduced by photodynamic AMC as shown by the reduced standard deviation. Photodynamic AMC therefore are not only suitable for reducing the microbial load in health care associated environments but also for closing hygiene gaps in public transportation.

\section{Materials and Methods}

Four urban buses of Regensburg (das Stadtwerk Regensburg GmbH, Regensburg, Germany) were selected showing comparable frequency of use. Six surfaces in all buses were exemplarily coated with the DYPHOX ${ }^{\circledR}$ technology (Dyphox, Regensburg, Germany), which should be frequently touched by passengers and/or bus drivers (Fig. 4). The buses were on the road from 5 a.m. to 2 p.m., which made it possible to map the traffic load at the core commute time, as the sampling took place immediately after the bus arrived at the terminal.

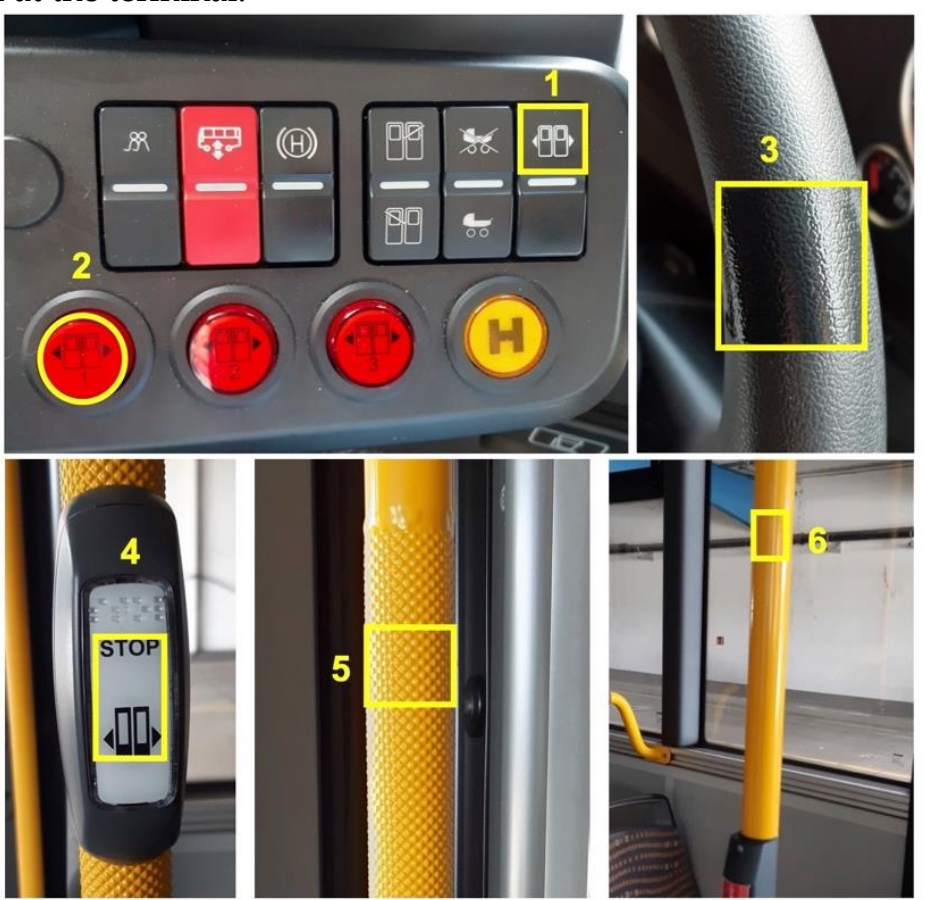

Figure 4. Sampling sites of the public transport buses. Sites 1-3 were surfaces frequently touched by the operator including two door opening buttons $(1,2)$ and the steering wheel (3). 
Sampling sites 4-6 were frequently touched surfaces in the passenger part of the bus, including a stop button (4), a textured handrail (5) and a non-textured handrail (6).

Inanimate surfaces in two buses received photodynamic coatings; in the other two buses the non-coated corresponding surfaces were used for sampling. The stability of all coatings was regularly checked at each sampling day during the field study by a visual examination of the macroscopic integrity of the applied coating.

Routine cleaning During the whole study, the routine cleaning procedures were left unchanged in the buses to avoid any potential bias on the study results. The buses were cleaned daily after the sampling was performed by first using a cleaning solution containing $<5 \%$ anionic surfactants followed up by treatment with $70 \%(\mathrm{v} / \mathrm{v})$ ethanol.

Sampling and quantification of bacteria The samples were collected over two months in 2021. The evaluation of bacterial counts was based on the European standard EN 13697 [48]. Collected samples were diluted in duplicates up to $10^{-2}$ and $500 \mu \mathrm{l}$ of each dilution were plated on tryptone-soy-agar (TSA). Colonies were counted after 24 and 48 $\mathrm{h}$, whereas only agar plates with a colony count of 14 to 330 were considered except for the undiluted sample. All tested surfaces were sampled using a liquid-based collection and transport system (eSwab regular, Mast Diagnostica GmbH, Reinfeld, Germany) according to the manufacturer's instructions. Counted values were converted into $\mathrm{cfu} / \mathrm{cm}^{2}$ depending on the size of the respective sampled area. For sampling surface 1, an area of 4 $\mathrm{cm}^{2}$ was sampled, surface 2 had a total sampling surface of $3.14 \mathrm{~cm}^{2}$, the sample from surface 3 was obtained from an area of $12 \mathrm{~cm}^{2}$, surface 4 was sampled on $6 \mathrm{~cm}^{2}$, surfaces 5 and 6 were sampled in a $16 \mathrm{~cm}^{2}$ area (Fig. 4). To ensure a sufficient bacterial contamination of the surfaces to be tested, prior to the study itself the $\mathrm{CFU} / \mathrm{cm}^{2}$ were evaluated on the same yet untreated surfaces over three days in two different buses.

Statistical Analysis All bacterial counts are presented as median and mean \pm SD. Values were compared between photodynamic coating and uncoated surface using the non-parametric Mann-Whitney U test. Bacterial counts were further dichotomized using the cut-offs $>5 \mathrm{cfu} / \mathrm{cm}^{2}$ and $>2.5 \mathrm{cfu} / \mathrm{cm}^{2}$. Absolute and relative risk reductions for high counts of bacteria on surfaces as well as odds ratios were calculated as effect estimates. Pvalue $<0.05$ was considered statistically significant. All analyses were performed using SPSS statistics software version 26.0.0 (IBM SPSS Software, Armonk, NY, USA).

Author Contributions: Conceptualization, D.B.E. and W.S.B.; methodology, L.K., P.B., D.B.E.; validation, D.B.E. and L.K.; formal analysis, D.B.E.; investigation, P.B. and L.K.; data curation, D.B.E.; writing - original draft preparation, D.B.E.; writing - review and editing, L.K. and W.S.B.; visualization, D.B.E.; supervision, D.B.E and W.S.B.; All authors have read and agreed to the published version of the manuscript.

Funding: Daniel B. Eckl was funded by the Deutsche Forschungsgemeinschaft (DFG, German Research Foundation) - Project number 415812443.

Data Availability Statement: Data is contained within the article

Acknowledgments: We thank das Stadtwerk Regensburg GmbH for the opportunity to conduct this study in the buses.

Conflicts of Interest: The authors declare no conflict of interest. The funders had no role in the design of the study; in the collection, analyses, or interpretation of data; in the writing of the manuscript, or in the decision to publish the results.

\section{References}

1. Ehrenberg, R. Urban microbes come out of the shadows. Nat. News 2015, 522, 399.

2. Afshinnekoo, E.; Meydan, C.; Chowdhury, S.; Jaroudi, D.; Boyer, C.; Bernstein, N.; Maritz, J.M.; Reeves, D.; Gandara, J.; Chhangawala, S. Geospatial resolution of human and bacterial diversity with city-scale metagenomics. Cell Syst. 2015, 1, 72-

87. 
3. Danko, D.; Bezdan, D.; Afshin, E.E.; Ahsanuddin, S.; Bhattacharya, C.; Butler, D.J.; Chng, K.R.; Donnellan, D.; Hecht, J.; Jackson, K. A global metagenomic map of urban microbiomes and antimicrobial resistance. Cell 2021.

4. Kang, K.; Ni, Y.; Li, J.; Imamovic, L.; Sarkar, C.; Kobler, M.D.; Heshiki, Y.; Zheng, T.; Kumari, S.; Wong, J.C.Y. The environmental exposures and inner-and intercity traffic flows of the metro system may contribute to the skin microbiome and resistome. Cell Rep. 2018, 24, 1190-1202.

5. Costello, C. Are "bad" microbes getting a free ride on your transit system?

6. Otter, J.A.; French, G.L. Bacterial contamination on touch surfaces in the public transport system and in public areas of a hospital in London. Lett. Appl. Microbiol. 2009, 49, 803-805.

7. Patel, K. V; Bailey, C.L.; Harding, A.; Biggin, M.; Crook, B. Background levels of micro-organisms in the busy urban environment of transport hubs. J. Appl. Microbiol. 2018, 125, 1541-1551.

8. Chowdhury, T.; Mahmud, A.; Barua, A.; Khalil, M.D.I.; Chowdhury, R.; Ahamed, F.; Dhar, K. Bacterial contamination on hand touch surfaces of public buses in Chittagong city, Bangladesh. J Env. Sci Toxicol Food Technol 2016, 10, 48-55.

9. Hernández, A.M.; Vargas-Robles, D.; Alcaraz, L.D.; Peimbert, M. Station and train surface microbiomes of Mexico City's metro (subway/underground). Sci. Rep. 2020, 10, 1-10.

10. Triadó-Margarit, X.; Veillette, M.; Duchaine, C.; Talbot, M.; Amato, F.; Minguillón, M.C.; Martins, V.; de Miguel, E.; Casamayor, E.O.; Moreno, T. Bioaerosols in the Barcelona subway system. Indoor Air 2017, 27, 564-575.

11. Lutz, J.K. Methicillin-Resistant Staphylococcus aureus on Public Transportation Vehicles: Sampler Performance, Prevalence, and Epidemiology 2011.

12. Turner, N.A.; Sharma-Kuinkel, B.K.; Maskarinec, S.A.; Eichenberger, E.M.; Shah, P.P.; Carugati, M.; Holland, T.L.; Fowler, V.G. Methicillin-resistant Staphylococcus aureus: an overview of basic and clinical research. Nat. Rev. Microbiol. 2019, 17, 203218.

13. Kanamori, H.; Rutala, W.A.; Weber, D.J. The role of patient care items as a fomite in healthcare-associated outbreaks and infection prevention. Clin. Infect. Dis. 2017, 65, 1412-1419.

14. Correa-Martinez, C.L.; Tönnies, H.; Froböse, N.J.; Mellmann, A.; Kampmeier, S. Transmission of vancomycin-resistant enterococci in the hospital setting: uncovering the patient-environment interplay. Microorganisms 2020, 8, 203.

15. Bäumler, W.; Eckl, D.; Holzmann, T.; Schneider-Brachert, W. Antimicrobial coatings for environmental surfaces in hospitals: a potential new pillar for prevention strategies in hygiene. Crit. Rev. Microbiol. 2021, 1-35, doi:10.1080/1040841X.2021.1991271.

16. Eichner, A.; Holzmann, T.; Eckl, D.B.; Zeman, F.; Koller, M.; Huber, M.; Pemmerl, S.; Schneider-Brachert, W.; Bäumler, W. Novel photodynamic coating reduces the bioburden on near-patient surfaces thereby reducing the risk for onward pathogen transmission: a field study in two hospitals. J. Hosp. Infect. 2020, 104, 85-91, doi:10.1016/j.jhin.2019.07.016.

17. Dancer, S.J. Controlling hospital-acquired infection: focus on the role of the environment and new technologies for decontamination. Clin. Microbiol. Rev. 2014, 27, 665-690.

18. White, L.F.; Dancer, S.J.; Robertson, C.; McDonald, J. Are hygiene standards useful in assessing infection risk? Am. J. Infect. Control 2008, 36, 381-384.

19. Dancer, S.J. How do we assess hospital cleaning? A proposal for microbiological standards for surface hygiene in hospitals. J. Hosp. Infect. 2004, 56, 10-15, doi:https://doi.org/10.1016/j.jhin.2003.09.017.

20. Kramer, A.; Assadian, O. Survival of microorganisms on inanimate surfaces. In Use of Biocidal Surfaces for Reduction of Healthcare Acquired Infections; Springer, 2014; pp. 7-26.

21. Van Doremalen, N.; Bushmaker, T.; Morris, D.H.; Holbrook, M.G.; Gamble, A.; Williamson, B.N.; Tamin, A.; Harcourt, J.L.; Thornburg, N.J.; Gerber, S.I. Aerosol and surface stability of SARS-CoV-2 as compared with SARS-CoV-1. N. Engl. J. Med. 2020, 382, 1564-1567.

22. Dhand, R.; Li, J. Coughs and sneezes: their role in transmission of respiratory viral infections, including SARS-CoV-2. Am. J. Respir. Crit. Care Med. 2020, 202, 651-659. 
23. Chowdhury, D.; Tahir, S.; Legge, M.; Hu, H.; Prvan, T.; Johani, K.; Whiteley, G.S.; Glasbey, T.O.; Deva, A.K.; Vickery, K. Transfer of dry surface biofilm in the healthcare environment: the role of healthcare workers' hands as vehicles. J. Hosp. Infect. 2018, 100, e85-e90.

24. Suleyman, G.; Alangaden, G.; Bardossy, A.C. The role of environmental contamination in the transmission of nosocomial pathogens and healthcare-associated infections. Curr. Infect. Dis. Rep. 2018, 20, 1-11.

25. Carling, P.C.; Parry, M.M.; Rupp, M.E.; Po, J.L.; Dick, B.; Von Beheren, S.; Group, H.E.H.S. Improving cleaning of the environment surrounding patients in 36 acute care hospitals. Infect. Control Hosp. Epidemiol. 2008, 29, $1035-1041$.

26. Clancy, C.; Delungahawatta, T.; Dunne, C.P. Hand hygiene-related clinical trials reported between 2014 and 2020 : a comprehensive systematic review. J. Hosp. Infect. 2021.

27. Shaban, R.Z.; Sotomayor-Castillo, C.F.; Malik, J.; Li, C. Global commercial passenger airlines and travel health information regarding infection control and the prevention of infectious disease: What's in a website? Travel Med. Infect. Dis. 2020, 33, 101528.

28. Lawson, A.; Vaganay-Miller, M.; Cameron, R. An Investigation of the General Population's Self-Reported Hand Hygiene Behaviour and Compliance in a Cross-European Setting. Int. J. Environ. Res. Public Health 2021, $18,2402$.

Green, L.R.; Selman, C.A.; Radke, V.; Ripley, D.; Mack, J.C.; Reimann, D.W.; Stigger, T.; Motsinger, M.; Bushnell, L. Food worker hand washing practices: an observation study. J. Food Prot. 2006, 69, 2417-2423.

30. Cairncross, S.; Hunt, C.; Boisson, S.; Bostoen, K.; Curtis, V.; Fung, I.C.H.; Schmidt, W.-P. Water, sanitation and hygiene for the prevention of diarrhoea. Int. J. Epidemiol. 2010, 39, i193-i205.

31. Freeman, M.C.; Stocks, M.E.; Cumming, O.; Jeandron, A.; Higgins, J.P.T.; Wolf, J.; Prüss-Ustün, A.; Bonjour, S.; Hunter, P.R.; Fewtrell, L. Systematic review: hygiene and health: systematic review of handwashing practices worldwide and update of health effects. Trop. Med. Int. Heal. 2014, 19, 906-916.

32. Mardiko, A.A.; von Lengerke, T. When, how, and how long do adults in Germany self-reportedly wash their hands? Compliance indices based on handwashing frequency, technique, and duration from a cross-sectional representative survey. Int. J. Hyg. Environ. Health 2020, 230, 113590.

33. Czeisler, M.É.; Garcia-Williams, A.G.; Molinari, N.-A.; Gharpure, R.; Li, Y.; Barrett, C.E.; Robbins, R.; Facer-Childs, E.R.; Barger, L.K.; Czeisler, C.A. Demographic Characteristics, Experiences, and Beliefs Associated with Hand Hygiene Among Adults During the COVID-19 Pandemic-United States, June 24-30, 2020. Morb. Mortal. Wkly. Rep. 2020, 69, 1485.

34. Makhni, S.; Umscheid, C.A.; Soo, J.; Chu, V.; Bartlett, A.; Landon, E.; Marrs, R. Hand Hygiene Compliance Rate During the COVID-19 Pandemic. JAMA Intern. Med. 2021.

35. ISO 22196:2011-08 Measurement of antibacterial activity on plastics and other non-porous surfaces. 2011.

36. ISO 21702:2019-05 Measurement of antiviral activity on plastics and other non-porous surfaces. 2019.

37. Michels, H.T.; Noyce, J.O.; Keevil, C.W. Effects of temperature and humidity on the efficacy of methicillin-resistant Staphylococcus aureus challenged antimicrobial materials containing silver and copper. Lett. Appl. Microbiol. 2009, 49, 191195.

38. Wainwright, M.; Maisch, T.; Nonell, S.; Plaetzer, K.; Almeida, A.; Tegos, G.P.; Hamblin, M.R. Photoantimicrobials - are we afraid of the light? Lancet Infect. Dis. 2017, 17, e49-e55, doi:10.1016/S1473-3099(16)30268-7.

39. Alquethamy, S.F.; Adams, F.G.; Naidu, V.; Khorvash, M.; Pederick, V.G.; Zang, M.; Paton, J.C.; Paulsen, I.T.; Hassan, K.A.; Cain, A.K. The role of zinc efflux during Acinetobacter baumannii infection. ACS Infect. Dis. 2019, 6, 150-158.

40. Williamson, D.A.; Carter, G.P.; Howden, B.P. Current and emerging topical antibacterials and antiseptics: agents, action, and resistance patterns. Clin. Microbiol. Rev. 2017, 30, 827-860.

41. EMA Reflection paper on antimicrobial resistance in the environment.

42. Pal, C.; Asiani, K.; Arya, S.; Rensing, C.; Stekel, D.J.; Larsson, D.G.J.; Hobman, J.L. Metal resistance and its association with antibiotic resistance. Adv. Microb. Physiol. 2017, 70, 261-313. 
43. Zhang, X.; Ma, J.; Chen, M.; Wu, Z.; Wang, Z. Microbial responses to transient shock loads of quaternary ammonium compounds with different length of alkyl chain in a membrane bioreactor. AMB Express 2018, 8, 1-10.

44. European Commission Chemicals Strategy for Sustainability Towards a Toxic-Free Environment Available online: https://ec.europa.eu/environment/pdf/chemicals/2020/10/Strategy.pdf.

45. Wang, K.-K.; Song, S.; Jung, S.-J.; Hwang, J.-W.; Kim, M.-G.; Kim, J.-H.; Sung, J.; Lee, J.-K.; Kim, Y.-R. Lifetime and diffusion distance of singlet oxygen in air under everyday atmospheric conditions. Phys. Chem. Chem. Phys. 2020, 22, 21664-21671.

46. Gunaydin, G.; Gedik, M.E.; Ayan, S. Photodynamic Therapy for the Treatment and Diagnosis of Cancer-A Review of the Current Clinical Status. Front. Chem. 2021, 608.

47. Nicolò, M.; Ferro Desideri, L.; Vagge, A.; Traverso, C.E. Current pharmacological treatment options for central serous chorioretinopathy: a review. Pharmaceuticals 2020, 13, 264.

48. DIN EN 13697:2019-10 Chemische Desinfektionsmittel und Antiseptika - Quantitativer Oberflächen-Versuch zur Bestimmung der bakteriziden und/oder fungiziden Wirkung chemischer Desinfektionsmittel auf nicht porösen Oberflächen in den Bereichen Lebensmittel, Industrie, Haushalt u. 2019, doi:https://dx.doi.org/10.31030/3054767. 